\title{
CytroCell: Valued Cellulose from Citrus Processing Waste
}

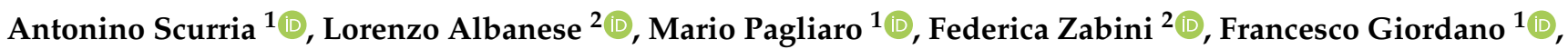 \\ Francesco Meneguzzo $2, *$ (D) and Rosaria Ciriminna $1, * \mathbb{D}$ \\ 1 Istituto per lo Studio dei Materiali Nanostrutturati, CNR, via U. La Malfa 153, 90146 Palermo, Italy; \\ antonino.scurria@ismn.cnr.it (A.S.); mario.pagliaro@cnr.it (M.P.); francesco.giordano@cnr.it (F.G.) \\ 2 Istituto per la Bioeconomia, CNR, via Madonna del Piano 10, 50019 Sesto Fiorentino, Italy; \\ lorenzo.albanese@cnr.it (L.A.); federica.zabini@cnr.it (F.Z.) \\ * Correspondence: francesco.meneguzzo@cnr.it (F.M.); rosaria.ciriminna@cnr.it (R.C.)
}

Citation: Scurria, A.; Albanese, L.; Pagliaro, M.; Zabini, F.; Giordano, F.; Meneguzzo, F.; Ciriminna, R. CytroCell: Valued Cellulose from Citrus Processing Waste. Molecules 2021, 26, 596. https://doi.org/ $10.3390 /$ molecules 26030596

Academic Editor: Alejandro Rodríguez Pascual

Received: 7 January 2021

Accepted: 19 January 2021

Published: 23 January 2021

Publisher's Note: MDPI stays neutral with regard to jurisdictional claims in published maps and institutional affiliations.

Copyright: (c) 2021 by the authors. Licensee MDPI, Basel, Switzerland. This article is an open access article distributed under the terms and conditions of the Creative Commons Attribution (CC BY) license (https:/ / creativecommons.org/licenses/by/ $4.0 /)$.

\begin{abstract}
Isolating cellulose from citrus processing waste without employing chemicals has so far been an unfulfilled goal of chemical research applied to the valorization of a widely available biowaste, annually totaling $>100$ million tonnes. We have applied hydrodynamic cavitation using a Venturi-type reactor for the extraction of all valued bioproducts of industrial citrus processing waste in water only, directly on a semi-industrial scale. After reporting the discovery of IntegroPectin in the soluble fraction of the aqueous extract, we now report the isolation of a cellulosic material in the water-insoluble fraction of cavitated lemon and grapefruit processing waste. Named "CytroCell", the material is cellulose of low crystallinity, high porosity, good water holding capacity and good dispersibility in water. These properties open the route to mass-scale production of a useful functional material from a cheap and abundant biowaste.
\end{abstract}

Keywords: cellulose; lemon; grapefruit; citrus processing waste; hydrodynamic cavitation; bioeconomy

\section{Introduction}

Citrus processing waste (CPW), namely citrus bagasse comprised of compressed peel, seeds and segmental membrane residual of the citrus juice industry, has long been identified as a potential source of multiple valued bioproducts, including cellulose [1,2]. Multiple chemical routes have been developed for the extraction of citrus cellulose from said byproduct, generally starting from treatment with soda to remove lignin and hemicellulose, either with ethylenediaminetetraacetic acid as chelating agent [3] or followed by bleaching with $4 \% \mathrm{H}_{2} \mathrm{O}_{2}$ under a basic condition at $90{ }^{\circ} \mathrm{C}$ [4]. Noting that the main use of $\mathrm{CPW}$ from orange and grapefruit juice production plants (over 10 million tonnes per year in the USA alone) is as low-value cattle feed obtained by energy-intensive drying of CWP, scholars in 2013 identified the integrated physico-chemical pretreatments of the biowaste, including high-speed grinding and treatment with caustic soda as the main challenges to the industrial development of the citrus biorefinery [5].

Beyond microcrystalline cellulose, waste orange peel has long been studied as a source of nanocellulose, namely a nanostructured material of exceptional mechanical (and thermal) properties ideally suited, if available at low cost and large amounts, for potentially numerous industrial applications [6], including carmaking using nanocellulose-based composites. Routes to nanocellulose derived from citrus processing waste include the use of enzymes [7], microwaves [8] and acids [9].

Nanocellulose has so far been industrially manufactured on small scale from bleached wood pulp in the form of nanofibrillated cellulose (also known as microfibrillated cellulose or cellulose nanofiber) after chemical delamination (fibrillation) of the cellulose fibers via TEMPO-mediated oxidation [9] (TEMPO is the 2,2,6,6-tetramethylpiperidine-1-oxyl radical that at buffered alkaline $\mathrm{pH}$ with hypochlorite as primary oxidant selectively oxidises 
the primary alcohol groups of the glucose units [10]). The nanomaterial is chiefly used in the paperboard and packaging industry to manufacture paperboard enhanced with microfibrillated cellulose in milk cartons for the dairy industry [11].

As explained by Guan and co-workers [6], biomass pretreatment to remove all noncellulosic material (lignin and pectin) from lignocellulosic biomass-requiring numerous chemical and mechanical steps followed by nanocellulose extraction via acid hydrolysis, generating large amounts of wastewater, high energy consumption for a mechanical process, or long reaction time for enzymatic hydrolysis-has so far impeded the mass-scale production of an exceptionally versatile biomaterial.

Perhaps the cleanest processes reported so far are the stepwise microwave hydrothermal treatment of dried depectinated orange peel from $120^{\circ} \mathrm{C}$ to $180^{\circ} \mathrm{C}$ to produce nanocellulose fibrils [8] and the autoclaving of lime processing waste at $110-130{ }^{\circ} \mathrm{C}$ to remove hemicellulose and pectin followed by high shear (at 20,000 rpm for $15 \mathrm{~min}$ ) and highpressure (at $40 \mathrm{MPa}$ for 5 passes) homogenizing [12]. Though demonstrated at the lab scale at low dried peel load ( $1 \mathrm{~g}$ of dried peel mixed with $70 \mathrm{~g}$ of distilled water), the nanocellulose obtained via the microwave hydrothermal treatment of dried depectinated orange peel had a high water retention capacity varying between 16 and $20 \mathrm{~g}_{\mathrm{H}_{2} \mathrm{O}} \mathrm{g}^{-1}$ but was deeply colored brown due to the Maillard reaction products formed from the degradation/caramelization of sugars and their further reaction with residual proteins at the high temperatures employed [8].

Hydrodynamic cavitation (HC) is increasingly applied in the extraction of natural products from multiple biomass sources [13]. In 2019, our teams applied a method to extract the main bioproducts of orange processing waste directly on a semi-industrial scale, i.e., processing $42 \mathrm{~kg}$ of wet waste orange peel (WOP) obtained from the citrus juice industry in $120 \mathrm{~L}$ water [14]. Focusing our initial attention on the water-soluble products resulting from the extraction, we isolated a unique form of pectin (named "IntegroPectin") with a low degree of esterification (17\%) and containing plentiful amounts of co-extracted orange flavonoids hesperidin and naringin, raising global interest in $\mathrm{HC}$ as an efficient and highly scalable hesperidin production method for the prevention or treatment of COVID-19 [15]. Shortly afterward, we extended the method on the same semi-industrial scale to lemon and grapefruit processing waste, isolating a lemon pectin showing exceptional antioxidant [16] and good antibacterial [17] properties and a grapefruit pectin showing even higher and broad-spectrum bactericidal action [18].

The only investigation carried out on the insoluble, cellulose-rich fraction obtained from HC of waste orange peel showed that the HC process was able to effectively increase the methane generation from the solid residues of the WOP material, with a clear increasing trend during the hydrocavitation process up to the full exploitation of the respective biochemical methane potential (BMP), reaching $+8 \%$ of the theoretical BMP for the hydrocavitated solid sample obtained after $270 \mathrm{~min}$ of cavitation [14]. Now, we report the first structural investigation of the cellulose-rich fraction isolated from the HC-based extraction of lemon and grapefruit industrial processing waste. This new biomaterial (see below) is named herein "CytroCell".

\section{Results and Discussion}

\subsection{Textural Properties}

The physisorption isotherms showing $\mathrm{N}_{2}$ adsorption at $77 \mathrm{~K}$ and at sub-atmospheric pressures in Figure 1 show that both lemon and grapefruit CytroCell are mesoporous materials (caveat: the high electrostatic charge on the surface of both celluloses is allowed to solely use an aggregate rather than a powdered specimen to carry out the experiments). The shape of the isotherms intermediate between type IV (irreversible type IV isotherm characteristic of mesoporous solids, with pore size $>2 \mathrm{~nm}$ ) and type II (reversible type II isotherm characteristic of macroporous solids with pore size $>50 \mathrm{~nm}$ ). The hysteresis loop of the resulting Type IVa isotherm for mesoporous materials with pore size $>4 \mathrm{~nm}$, located in the multilayer range of the isotherm, is associated with said capillary condensation [19]. 

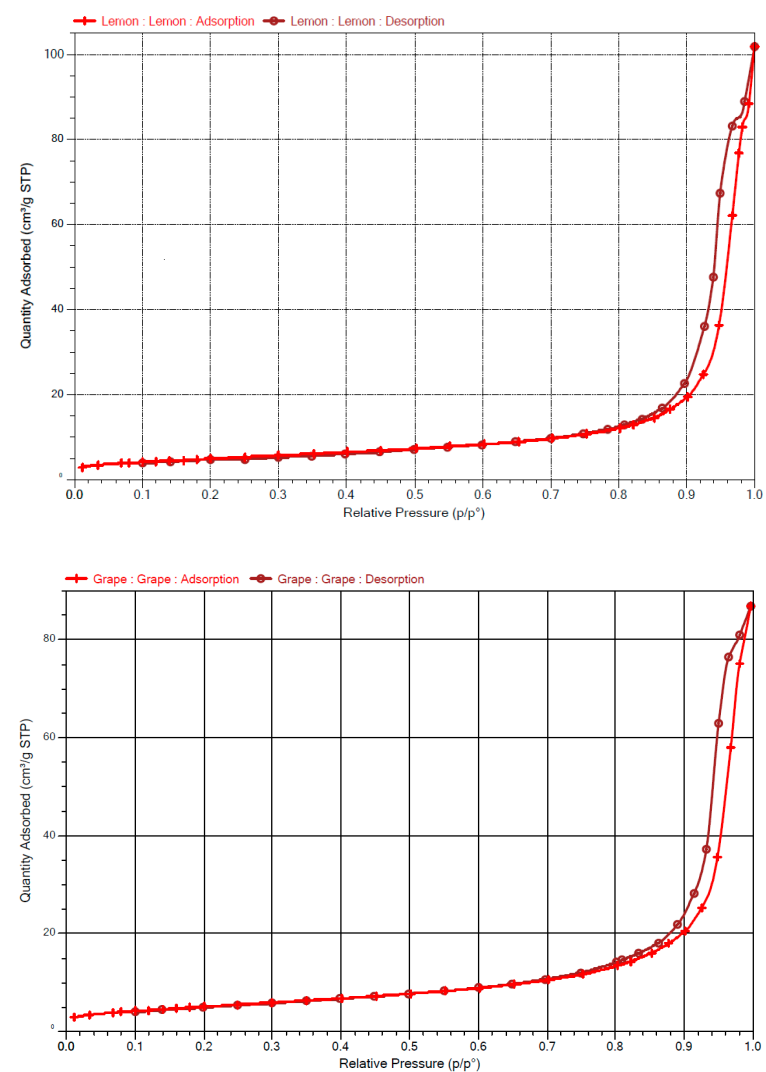

Figure 1. Low-temperature $\mathrm{N}_{2}$ adsorption-desorption isotherms for lemon (top) and grapefruit (bottom) CytroCell.

Comparison of the pore size and specific pore volume obtained via the classical pore size model developed by Barret, Joyner and Halenda (BJH) from the adsorption and desorption branches of the isotherms shows similar values for both celluloses, with the exception of the pore size of lemon CytroCell measured on the adsorption branch, which is $2 \mathrm{~nm}$ larger than the pore size measured on the desorption branch (entries 1 and 2 in Table 1).

Table 1. Specific pore volume and pore size for lemon and grapefruit CytroCell.

\begin{tabular}{cccc}
\hline Entry & Sample & $\begin{array}{c}\text { Specific Pore Volume } \\
\left(\mathbf{c m}^{3} / \mathbf{g}\right)\end{array}$ & $\begin{array}{c}\text { Pore Size } \\
(\mathbf{n m})\end{array}$ \\
\hline $\mathbf{1}$ & Lemon CytroCell & $0.137^{\mathrm{a}}$ & $29.49^{\mathrm{a}}$ \\
$\mathbf{2}$ & Lemon CytroCell & $0.137^{\mathrm{b}}$ & $27.34^{\mathrm{b}}$ \\
$\mathbf{3}$ & Grapefruit CytroCell & $0.117^{\mathrm{a}}$ & $23.63^{\mathrm{a}}$ \\
$\mathbf{4}$ & Grapefruit CytroCell & $0.125^{\mathrm{b}}$ & $23.96^{\mathrm{b}}$ \\
\hline
\end{tabular}

a From the Barret, Joyner and Halenda (BJH) adsorption branch; ${ }^{\mathrm{b}}$ from the BJH desorption branch.

Coupled with the shape of the isotherms, these results indicate that the citrus structure of CytroCell includes large and open mesopores with a broad size distribution as observed in the case of certain tropical wood aerogels [20]. The pore size from the desorption branch, indeed, corresponds to the aperture (entrance) size of the pore, whereas the pore size distribution (Figure 2) obtained from the adsorption branch of the isotherm corresponds to the size of the cavity [21]. 

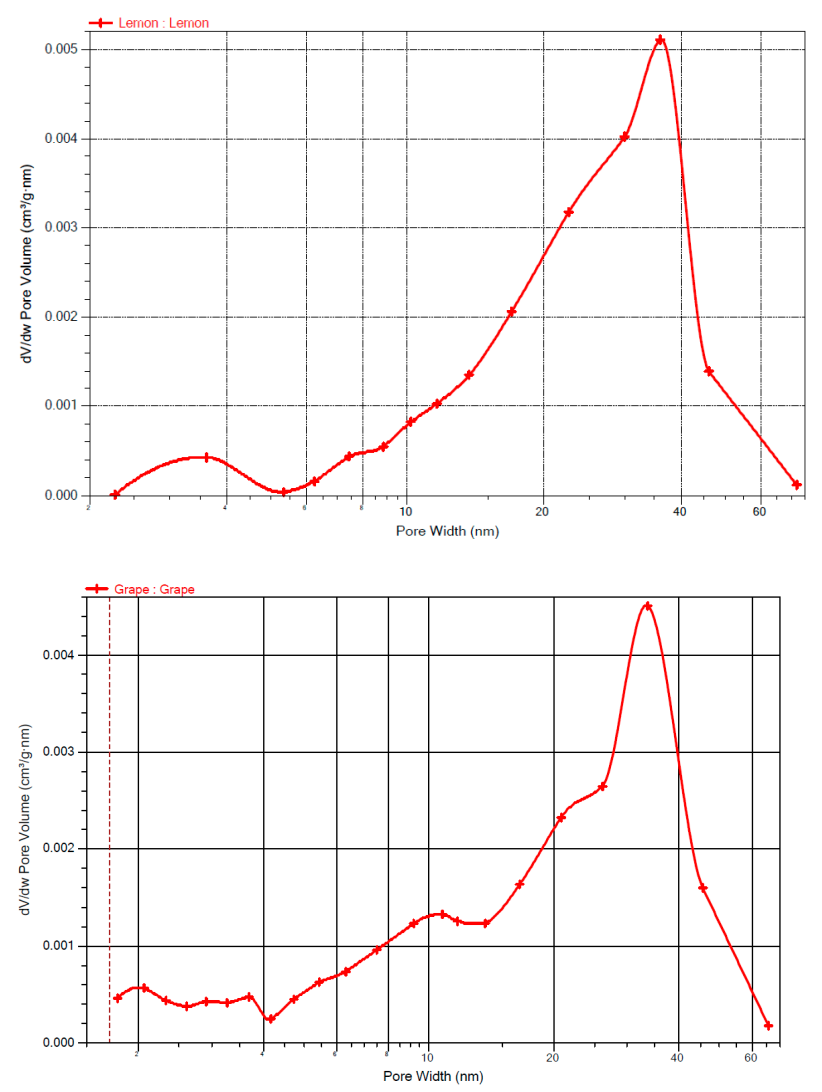

Figure 2. Pore size distribution for lemon (top) and grapefruit (bottom) CytroCell from the respective $\mathrm{BJH}$ isotherm desorption branch.

Like the aforementioned tropical wood aerogels [20], the very narrow hysteresis loops in Figure 1, with the adsorption and desorption branches almost vertical and nearly parallel above 0.9 relative pressure, indicates the relatively large outer surface for both celluloses.

\subsection{IR Spectroscopy}

The FTIR spectra in Figure 3 display all the characteristic cellulose peaks (Table 2), including those in the fingerprint region of $1000-1200 \mathrm{~cm}^{-1}[22,23]$.

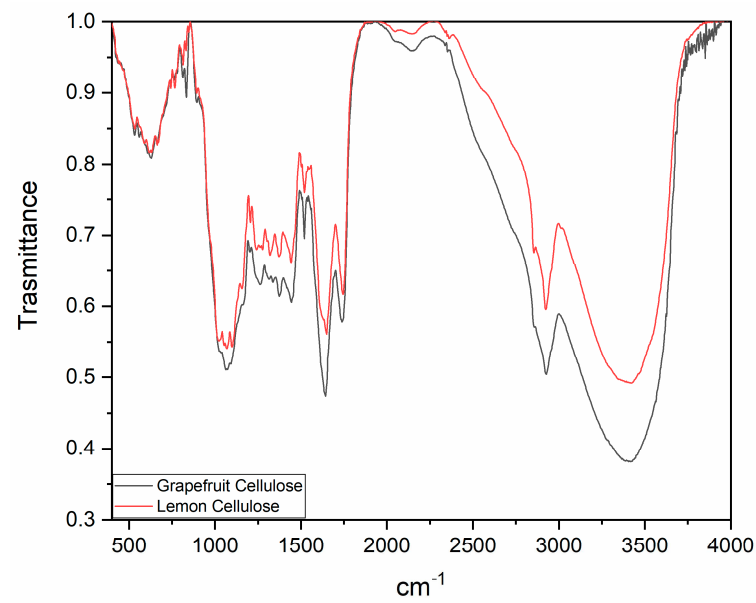

Figure 3. IR spectra for for lemon (red) and grapefruit (black) CytroCell. 
Table 2. Selected absorption bands and corresponding vibrational modes of chemical groups in cellulose in the IR absorption spectrum of cellulose ${ }^{a}$ (Adapted from Refs. [22] and [23], CC BY license).

\begin{tabular}{cc}
\hline Wavenumber of Absorption Bands $\left.\mathbf{( c m}^{-\mathbf{1}}\right)$ & Chemical Group \\
\hline $3300-3400$ & $v \mathrm{OH}$ covalent bond, hydrogen bonding \\
$2850-2925$ & $v \mathrm{CH}, \mathrm{CH} \mathrm{H}_{2}$ \\
1641 & absorbed water (hydrogen-bonded) \\
1428 & $\delta \mathrm{CH}_{2}$ (symmetric) at $\mathrm{C}-6$; crystalline region \\
1236 & $\delta \mathrm{COH}$ in plane at $\mathrm{C}-6$ \\
1160 & $v \mathrm{COC}$ at $\beta$-glycosidic linkage \\
1104 & $v(\mathrm{C}-\mathrm{O}-\mathrm{C})$ in ring \\
1030 & $v \mathrm{CO}$ at $\mathrm{C}-6$ \\
897 & $v \mathrm{COC}$ at $\beta$-glycosidic linkage, amorphous \\
662 & region \\
\hline
\end{tabular}

The broad band around $3330-3400 \mathrm{~cm}^{-1}$ corresponds to the stretching vibrations of $\mathrm{O}-\mathrm{H}$ bonds of free and bound water and $\mathrm{O}-\mathrm{H}$ bonds of hydroxyl groups [24]. The bands at $2850-2925 \mathrm{~cm}^{-1}$ are due to the stretching vibrations of the $\mathrm{C}-\mathrm{H}$ bonds in the saturated carbon rings of polysaccharides and to the stretching vibrations of these bonds in $\mathrm{CH}_{2}$ groups [24]. The signal at $1160 \mathrm{~cm}^{-1}$ wavelength derives from the stretching vibration of the C-O-C $\beta-(1-4)$-glycosidic bond as well as to the stretching vibrations of $\mathrm{C}-\mathrm{O}$ bonds in saturated six-membered rings, whereas the signal at $897 \mathrm{~cm}^{-1}$ is due to $v \mathrm{C}-\mathrm{O}-\mathrm{C}$ at the same glycosidic linkage from the amorphous region of cellulose [25].

The bands at $1650 \mathrm{~cm}^{-1}$ and at $1730 \mathrm{~cm}^{-1}$ are not due to pectin, which is efficiently separated from the lignocellulosic biomass and solubilized in water during the cavitationbased extraction process, but rather to the free and esterified carboxyl groups of cellulose esterified with citric acid upon reaction of the citric acid residual in the wet lemon (and in the wet grapefruit) bagasse and the primary alcohol groups of cellulose (Scheme 1) [26].

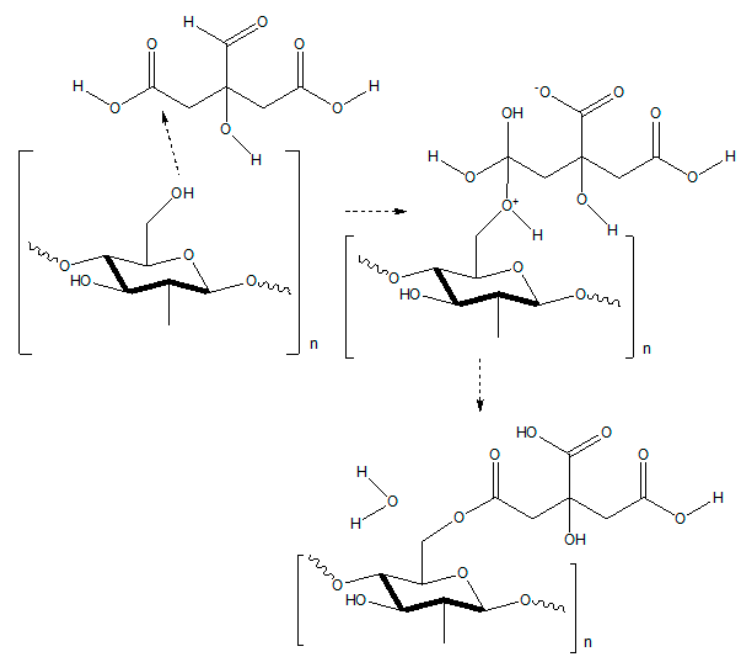

Scheme 1. Esterification of cellulose primary alcohol groups and citric acid.

Remarkably, the same peaks were observed and ascribed to the same esterified groups by scholars in Turkey analyzing a lemon resin obtained by boiling small pieces of lemon fruit [27], as well as by Brazilian scholars producing nanocellulose by reacting wood cellulose pulp with aqueous citric acid at $120^{\circ} \mathrm{C}$ [28].

We make the hypothesis that the extreme conditions created in the imploding cavitation bubbles ease the reaction of citric acid with the primary hydroxyl group of cellulose chains to form an ester bond like what happens in the latter process eventually affording 
partly esterified cellulose. Citric acid also plays a crucial role in converting the residual lignin in the waste citrus peel by creating an catalytic environment [8] similar to that of the microwave-assisted extraction able to hydrolyze lignin via proton transfer, $\beta$-elimination and ester/ether cleavage [8].

\subsection{X-ray Diffraction}

The XRD spectra in Figure 4 display all the characteristic diffraction peaks of cellulose from citrus waste with the $16.4^{\circ}$ peak (101 plane), which can be separated into amorphous and crystalline portions, an amorphous region between $16.4^{\circ}$ and $18.0^{\circ}$, and the highest peak at $22 \cdot 4^{\circ}$ corresponding to diffraction from the 002 plane $[8,29]$.

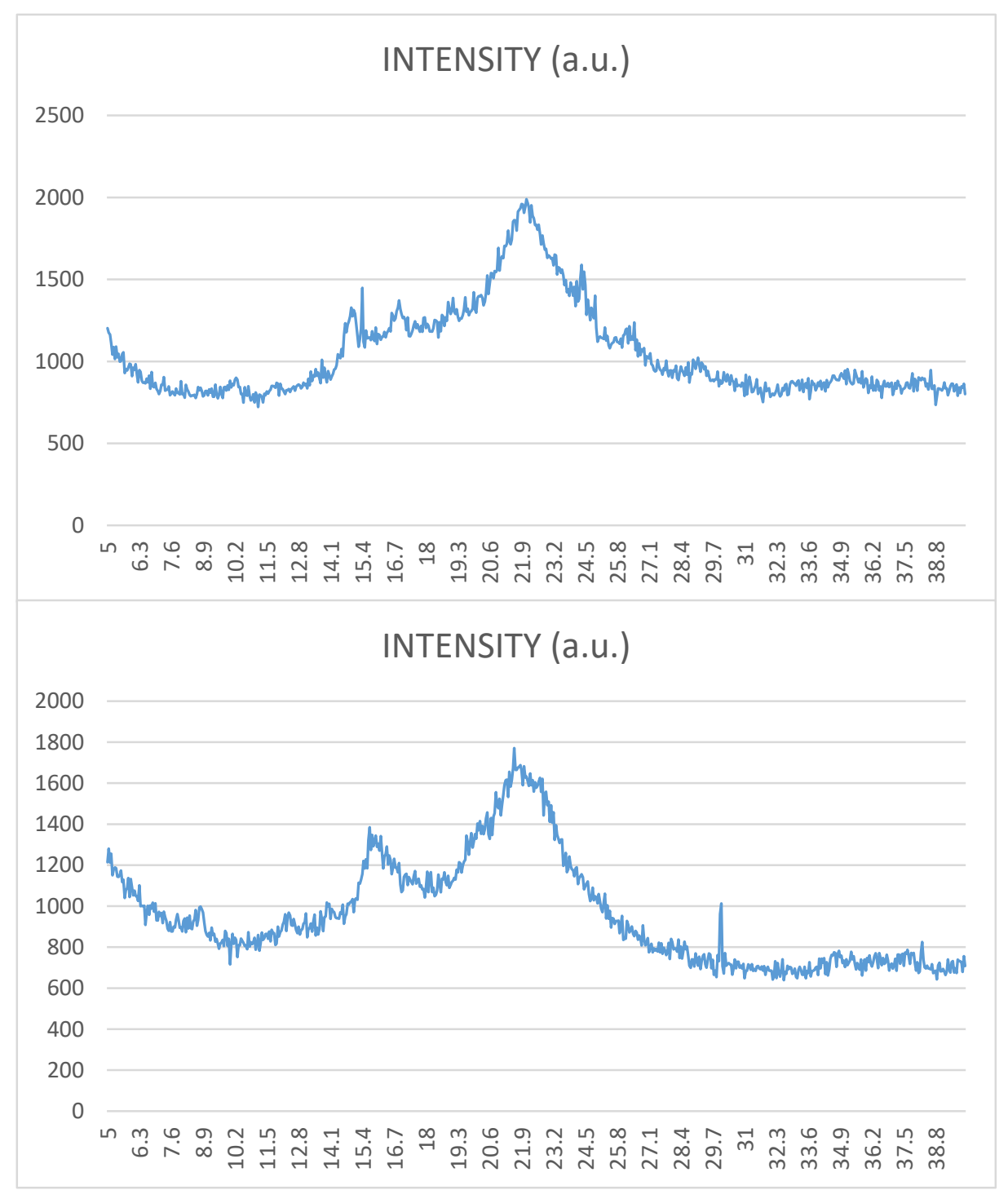

Figure 4. XRD spectra for lemon (top) and grapefruit (bottom) CytroCell.

The crystallinity index (CI) readily calculated using the Segal equation (Equation (1)), namely the ratio between the difference between the 002-peak intensity $\left(I_{002}\right)$ and the intensity $I_{\mathrm{am}}$ of diffraction $2 \vartheta=18^{\circ}$ corresponding to the proportion of the amorphous cellulose [29]:

$$
\mathrm{CI}=\left(I_{002}-I_{\mathrm{am}}\right) / I_{002}
$$


Using the intensity arbitrary units from the diffractograms displayed in Figure 4, the aforementioned equation returns exceptionally low levels values for the CI of 0.33 for lemon CytroCell (Equation (2)) and 0.36 for grapefruit CytroCell (Equation (3)):

$$
\begin{aligned}
& \mathrm{CI}(\text { lemon CytroCell })=(1650-1100)) / 1650 \simeq 0.33 \\
& \mathrm{CI}(\text { grapefruit CytroCell })=(1950-1250) / 1950 \simeq 0.36
\end{aligned}
$$

This points to a key role of citric acid (far more abundant in lemon) during the hydrodynamic cavitation of the wet industrial waste of the citrus juice industry, analogous to what was observed in the conversion of the key citrus terpenes limonene and linalool [30]. For comparison, the crystallinity index of orange bagasse nanocellulose obtained upon enzymatic hydrolysis of bacterial cellulose is 0.63 [7], still significantly lower than that of cotton nanofibers, which have a CI of 0.78 [31]. Causing such a low CI value, we hypothesize, are the extreme pressure and temperature local conditions determined by the implosion of the cavitation bubbles. This defibrillates the cellulose fibers and alters the crystalline morphology of native citrus cellulose. Subsequent microscopic investigation will investigate the validity of this hypothesis.

Like what was observed for citrus depectinated nanocellulose obtained via microwaveassisted extraction [6], peaks at about $15^{\circ}, 24^{\circ}$ and $30^{\circ}$ deriving from $\mathrm{CaC}_{2} \mathrm{O}_{4}$ were observed in the XRD spectra, particularly in the case of grapefruit CytroCell (Figure 4, bottom). Calcium oxalate crystals are ubiquitous in many plants (in widely different parts of the plant, from leaves to roots) where they exert multiple functions against both abiotic (drought, nutrient deprivation, metal toxicity) and biotic (pathogens and herbivore) stress factors [32].

\subsection{Zeta Potential}

The results of the zeta potential, an indirect measure of the net charge of particles in suspension, which indicates the stability of a suspension (the larger the $\zeta$ potential absolute value, the more stable the colloidal dispersion), displayed in Table 3 point to a negative value approaching $-30 \mathrm{mV}$ for lemon CytroCell and $-23 \mathrm{mV}$ for grapefruit CytroCell.

Table 3. $\zeta$ potential for lemon and grapefruit CytroCell obtained using hydrodynamic cavitation.

\begin{tabular}{cc}
\hline Material & Zeta Potential (mV) \\
\hline Lemon CytroCell & -29.5 \\
Grapefruit CytroCell & -22.67 \\
\hline
\end{tabular}

In agreement with guidelines classifying nanoparticle dispersions derived from the Derjaguin, Landau, Verwey and Overbeek theory of colloids, this indicates that lemon CytroCell nanoparticles are highly stable $(\zeta> \pm 30 \mathrm{mV})$, whereas grapefruit CytroCell particles $( \pm 20<\zeta<30 \mathrm{mV})$ are moderately stable [33]. These values of the potential are close to those of wood nanocellulose obtained after the hydrothermal treatment of commercial cellulose with citric acid for $1.5 \mathrm{~h}(-36.5 \mathrm{mV}$ [28]), ascribed to the presence of anionic carboxyl groups at the surface of nanocellulose, imparting increased electrostatic repulsion and thus enhanced stability of the colloidal suspension.

\subsection{Water Holding Capacity}

We measured the water holding (or retention) capacity (WHC) for both grapefruit and lemon CytroCell by leaving for $30 \mathrm{~min}$ a sample of mildly dried CytroCell with distilled water in a centrifuge tube. After centrifugation, the water retention capacity of lemon CytroCell was $8 \mathrm{~g}_{\text {water }} / \mathrm{g}_{\text {cell }}$, whereas that of grapefruit CytroCell was $5 \mathrm{~g}_{\text {water }} / \mathrm{g}_{\text {cell }}$. The water holding (or retention) capacity (of cellulose is a key parameter affecting the applications of cellulose in the food, pharmaceutical and cosmetic industries. In general, the WHC increases with increasing fiber length. For example, for powdered cellulose $(70 \%$ crystalline and 30\% amorphous), the WHC quickly increases between $4 \mathrm{~g}_{\text {water }} / \mathrm{g}_{\text {cell }}$ and 9.5 
$\mathrm{g}_{\text {water }} / \mathrm{g}_{\text {cell }}$ for fibers between $35 \mu \mathrm{m}$ and $110 \mu \mathrm{m}$, whereas it remains virtually constant for fibers shorter than $35 \mu \mathrm{m}$ and longer than $110 \mu \mathrm{m}$ [34].

Showing the large applicative potential of these new nanocelluloses due to their WHC, Figure 5 shows a disc of lemon CytroCell readily obtained upon mildly drying a dispersion of the material in water overnight at $35^{\circ} \mathrm{C}$. The porous and fibrous nature of the lightweight biomaterial is readily recognized. With nonuniform distribution of composition materials, the film is displayed only to demonstrate the ease with which the CytroCell aggregates forming a rigid film of significant thickness and strength. Subsequent work will use purified CytroCell to shape films of uniform size and composition reporting the mechanical and thermal properties for both CytroCell materials.

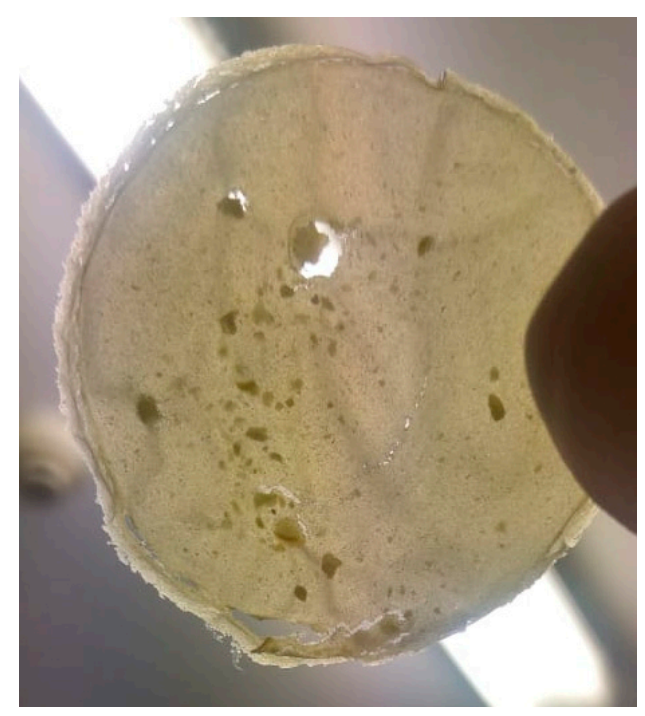

Figure 5. Disc of lemon CytroCell obtained upon mild drying of an aqueous paste.

\section{Materials and Methods}

\subsection{Materials Preparation}

The raw materials (integral aqueous extracts of lemon and grapefruit bagasse) were obtained by means of hydrodynamic cavitation processes lasting $60 \mathrm{~min}$ as in previous experiments [14]. The HC extraction device included a closed hydraulic loop (total volume capacity around 230 L), a centrifugal pump (Lowara, Vicenza, Italy, ESHE 50-160/75) with $7.5 \mathrm{~kW}$ nominal mechanical power and rotation speed of $2900 \mathrm{rpm}$ and a Venturi-shaped sealed reactor to minimize the loss of the lemon and grapefruit processing waste's volatile components [16]. In detail, $34 \mathrm{~kg}$ of fresh waste lemon peel obtained from organically grown Siracusa lemons (Citrus limon, cultivar "femminello") by an in-line extractor at a juice factory kindly donated by a citrus company based in Sicily were first ground in ice with an electric blender and then added along with $120 \mathrm{~L}$ of tap water to the HC device. The reactor was closed and cavitation started. The whole process lasted $60 \mathrm{~min}$ and consumed $6.70 \mathrm{kWh}$ of electric energy, thus the specific consumed energy was $0.22 \mathrm{kWh}$ per $\mathrm{kg}$ of fresh lemon processing waste. After completion, the liquid phase was collected and lyophilized to obtain the lemon IntegroPectin [16]. Prior to lyophilization, the insoluble cellulosic material in the cavitated aqueous mixture was filtered using a Büchner filter with Whatman ashless filter paper, grade 589/3. The aqueous phase was used to isolate IntegroPectin via lyophilization [16] while CytroCell cellulose was isolated from the filtered wet solid phase. A filtrate sample $(50 \mathrm{~g})$ including plentiful adsorbed water was mixed with $150 \mathrm{~mL}$ of distillate water under fast stirring $(470 \mathrm{rpm})$ for $30 \mathrm{~min}$ using a KS 260 control flat shaker (IKA-Werke, Staufen, Germany). The washed material was further refined by pressing the cellulosic paste through the mesh of a laboratory test sieve (aperture of $212 \mu \mathrm{m}$, Endecotts, London, Great Britain) using a flat glass specimen. The refined material was 
dried in an oven at $35^{\circ} \mathrm{C}$ for $20 \mathrm{~h}$. The amount of isolated dried lemon and grapefruit CytroCell was $1.2 \mathrm{~g}$ and $1.7 \mathrm{~g}$, respectively.

\subsection{Water Holding Capacity}

To measure the water retention capacity, a sample of dried CytroCell $(1 \mathrm{~g})$ was mixed with $15 \mathrm{~mL}$ of deionized water and poured into two $20 \mathrm{~mL}$ centrifuged tubes. The two samples were stirred for $10 \mathrm{~min}$ and then centrifuged at $3000 \mathrm{rpm}$ for $30 \mathrm{~min}$ using an Allegra $\mathrm{X}-22 \mathrm{R}$ benchtop centrifuge (Beckman Coulter, Palo Alto, CA, USA). After centrifugation, the supernatant aqueous phase was removed and the wet cellulose was weighed.

\subsection{FT-IR Analyses}

The IR analyses were performed with an ALPHA compact FT-IR spectrometer (Bruker Optics, Billerica, MA, USA). Each time, a sample of a few mg of lemon or grapefruit CytroCell cellulose in powder form was mixed with ultrapure KBr (FT-IR grade, $\geq 99 \%$ trace metals basis, Sigma-Aldrich, St. Louis, MI, USA). A small amount (ca. $20 \mathrm{mg}$ ) of CytroCell was mixed with an excess of $\mathrm{KBr}$ powder (ca. $150 \mathrm{mg}$ ) and ground using a pestle in an agate mortar to form a uniform mixture. A Specac Mini-Pellet laboratory hydraulic press was used for the preparation of high-quality $7 \mathrm{~mm} \mathrm{KBr}$ pellets for transmission FTIR (Figure 6) applying a $12 \mathrm{t}$ weight for $5 \mathrm{~min}$.

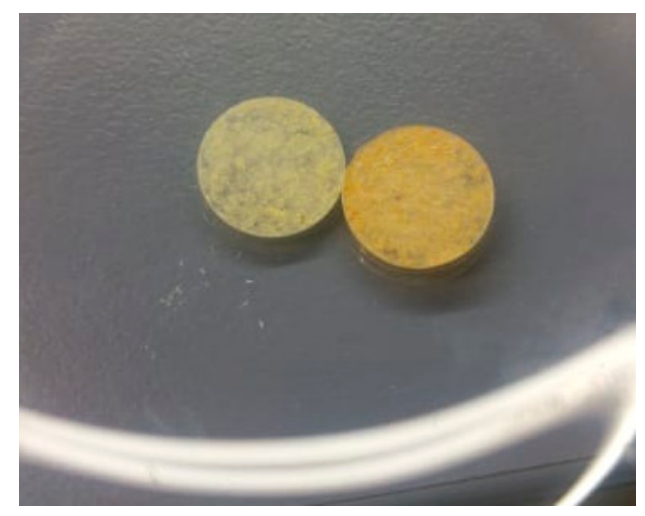

Figure 6. Pellets of lemon (yellow) and grapefruit (orange) CytroCell dispersed in KBr.

\subsection{XRD Analysis}

The samples were analyzed by a D5005 X-ray diffractometer (Bruker AXS, Karlsruhe, Germany) operating at $40 \mathrm{kV}$ and $30 \mathrm{~mA}$ to obtain the diffraction profile at $0.15^{\circ} / \mathrm{min}$ acquisition rate over a $5.0^{\circ}-40.0^{\circ} 2 \theta$ range. The $\mathrm{X}$-ray radiation was generated via a copper $(\mathrm{K} \alpha)$ anode and made monochromatic via the instrument's secondary monochromator.

\subsection{Nitrogen Physisorption Measurements}

The nitrogen adsorption isotherms were obtained using an ASAP 2020 Plus surface area and porosimetry system (Micromeritics Instrument Corporation, Norcross, GA, USA) equipped with the ASAP 2020 Plus Version 1.03 software. An aggregate sample of CytroCell (110.5 mg for grapefruit CytroCell and $93.5 \mathrm{mg}$ for lemon CytroCell) inserted in a glass burette was first degassed by heating it for $10 \mathrm{~min}$ with a heating ramp rate of $10^{\circ} \mathrm{C} / \mathrm{min}$. The analysis was carried out at $77.423 \mathrm{~K}$ with a $10 \mathrm{~s}$ equilibration interval.

\subsection{Disc Preparation}

The same hydrated sample obtained after prolonged contact of $200 \mathrm{mg}$ grapefruit or lemon CytroCell cellulose with water after centrifugation in the WRC test was added with $5 \mathrm{~mL}$ distillate water. After short homogenization using a vortex shaker (Vortex 1, IKA-Werke, Staufen, Germany), the mixture was dried in an oven at $35^{\circ} \mathrm{C}$ for $20 \mathrm{~h}$. 


\subsection{Zeta potential}

The zeta potential was determined at $25{ }^{\circ} \mathrm{C}$ with a Zetasizer Nano ZS analyzer (Malvern Panalytical, Malvern, Great Britain) using a laser wavelength of $633 \mathrm{~nm}$ to measure the speed of particle movement using laser Doppler electrophoresis. A suspension of CytroCell $(20 \mathrm{mg})$ in $10 \mathrm{~mL}$ millQ water was employed in the measurements carried out in a DTS1070 cell. The zeta potential reported is the average of three measurements, which returned very similar results.

\section{Conclusions}

We have discovered a new form of citrus cellulose of low crystallinity index, large open mesoporosity, good water retention capacity and dispersibility in water, which can be easily synthesized in large amounts by hydrodynamic cavitation of citrus processing biowaste. Named "CytroCell", this new form of cellulose studied herein originating from lemon and grapefruit bagasse has ultralow crystallinity of about 0.35 , large mesoporosity (pore size close to or even exceeding $25 \mathrm{~nm}$ ) and good water holding capacity approaching almost $10 \mathrm{~g}_{\text {water }} / \mathrm{g}_{\text {cell }}$ in the case of lemon CytroCell). Part of the cellulose fibrils, we argue in this study, are esterified with citric acid, abundant in the wet residue of lemon and grapefruit industrial juice production used as raw material. The biomaterial obtained from the food industry waste rather than from wood pulp is suitable for a wide variety of applications. The large pore diameter around $24 \mathrm{~nm}$ for both celluloses, for example, makes them suitable for catalysis (as metal support), separation (chromatography) and adsorption (decontamination) using an intrinsically sustainable biomaterial.

Carried out in water only, the physical production route does not require any pretreatment of citrus processing waste and does not use acid, alkali, chemical oxidants or enzymes, thereby establishing an intrinsically green production route for cellulose starting from biobased waste available worldwide in over 110-120 million tonnes [35] using an easily scalable and low operating cost process increasingly employed for the extraction of numerous natural products $[13,14]$. The technology meets all six principles of Green Extraction of natural products [36]: (i) use of renewable, plentiful plant resources; (ii) solvent-free-water is the only solvent; (iii) low energy consumption; (iv) zero waste; (v) reduced unit operations in favor of safe, robust and scalable and easily controllable processes (only two operations (i.e., HC processing and mechanical separation); (vi) aims for a non-denatured and biodegradable extract without contaminants (absence of additives, water and raw materials are the only ingredient), while the HC-based process does not denaturate the bioactive compounds.

Author Contributions: Conceptualization, R.C., F.M., and M.P.; methodology, F.M., F.Z., L.A., R.C.; software, F.G.; formal analysis, F.G., R.C., F.M., M.P.; investigation, A.S. and F.G.; resources, F.M., M.P.; data curation, F.M., F.Z., R.C.; writing-original draft preparation, R.C.; writing-review and editing, F.M.; supervision, R.C., F.M.; funding acquisition, F.M., R.C. All authors have read and agreed to the published version of the manuscript.

Funding: This research received no external funding.

Data Availability Statement: All Data available by contacting the corresponding authors.

Acknowledgments: This study is dedicated to the memory of Herman van Bekkum (1932-2020), Technische Universiteit Delft, a pioneer in catalysis research applied to carbohydrate selective conversions. We thank Nunzio Gabriele Gallì, Istituto per lo Studio dei Materiali Nanostrutturati, CNR, for the nitrogen physisorption measurements. Thanks to OPAC Campisi (Siracusa, Italy) for kindly providing the lemon and grapefruit bagasse from which the CytroCell celluloses were obtained.

Conflicts of Interest: The authors declare no conflict of interest.

Sample Availability: Samples of the compounds are available from the authors. 


\section{References}

1. López, J.Á.S.; Li, Q.; Thompson, I.P. Biorefinery of waste orange peel. Crit. Rev. Biotechnol. 2010, 30, 63-69. [CrossRef] [PubMed]

2. Zema, D.; Calabrò, P.S.; Folino, A.; Tamburino, V.; Zappia, G.; Zimbone, S. Valorisation of citrus processing waste: A review. Waste Manag. 2018, 80, 252-273. [CrossRef] [PubMed]

3. Bicu, I.; Mustata, F. Optimization of isolation of cellulose from orange peel using sodium hydroxide and chelating agents. Carbohydr. Polym. 2013, 98, 341-348. [CrossRef] [PubMed]

4. Santonocito, A.M.; Vismara, E. Production of Textile from Citrus Fruit. U.S. Patent WO2015018711A1, 26 September 2017.

5. Rivas-Cantu, R.C.; Mills, P.L.; Jones, K.D. A citrus waste-based biorefinery as a source of renewable energy: Technical advances and analysis of engineering challenges. Waste Manag. Res. 2013, 31, 413-420. [CrossRef] [PubMed]

6. Phanthong, P.; Reubroycharoen, P.; Hao, X.; Xu, G.; Abudula, A.; Guan, G. Nanocellulose: Extraction and application. Carbon Resour. Convers. 2018, 1, 32-43. [CrossRef]

7. Mariño, M.; Da Silva, L.L.; Durán, N.; Tasic, L. Enhanced Materials from Nature: Nanocellulose from Citrus Waste. Molecules 2015, 20, 5908-5923. [CrossRef]

8. De Melo, E.M.; Clark, J.H.; Matharu, A.S. The Hy-MASS concept: Hydrothermal microwave assisted selective scissoring of cellulose for in situ production of (meso)porous nanocellulose fibrils and crystals. Green Chem. 2017, 19, 3408-3417. [CrossRef]

9. Naz, S.; Ahmad, N.; Akhtar, J.; Ahmad, N.M.; Ali, A.; Zia, M. Management of citrus waste by switching in the production of nanocellulose. IET Nanobiotechnol. 2016, 10, 395-399. [CrossRef]

10. De Nooy, A.E.J.; Besemer, A.C.; Van Bekkum, H. On the Use of Stable Organic Nitroxyl Radicals for the Oxidation of Primary and Secondary Alcohols. Synthesis 1996, 1996, 1153-1176. [CrossRef]

11. Stora Enso, MFC for Packaging. 2020. Available online: https://www.storaenso.com/en/products/bio-based-materials/mfcfor-packaging (accessed on 7 January 2020).

12. Jongaroontaprangsee, S.; Chiewchan, N.; Devahastin, S. Production of nanocellulose from lime residues using chemical-free technology. Mater. Today Proc. 2018, 5, 11095-11100. [CrossRef]

13. Panda, D.; Manickam, S. Cavitation Technology-The Future of Greener Extraction Method: A Review on the Extraction of Natural Products and Process Intensification Mechanism and Perspectives. Appl. Sci. 2019, 9, 766. [CrossRef]

14. Meneguzzo, F.; Brunetti, C.; Fidalgo, A.; Ciriminna, R.; DeLisi, R.; Albanese, L.; Zabini, F.; Gori, A.; Nascimento, L.B.D.S.; De Carlo, A.; et al. Real-Scale Integral Valorization of Waste Orange Peel via Hydrodynamic Cavitation. Processes $2019,7,581$. [CrossRef]

15. Meneguzzo, F.; Ciriminna, R.; Zabini, F.; Pagliaro, M. Review of Evidence Available on Hesperidin-Rich Products as Potential Tools against COVID-19 and Hydrodynamic Cavitation-Based Extraction as a Method of Increasing Their Production. Processes 2020, 8, 549. [CrossRef]

16. Nuzzo, D.; Cristaldi, L.; Sciortino, M.; Albanese, L.; Scurria, A.; Zabini, F.; Lino, C.; Pagliaro, M.; Meneguzzo, F.; Di Carlo, M.; et al. Exceptional Antioxidant, Non-Cytotoxic Activity of Integral Lemon Pectin from Hydrodynamic Cavitation. ChemistrySelect 2020, 5, 5066-5071. [CrossRef]

17. Presentato, A.; Scurria, A.; Albanese, L.; Lino, C.; Sciortino, M.; Pagliaro, M.; Zabini, F.; Meneguzzo, F.; Alduina, R.; Nuzzo, D.; et al. Superior Antibacterial Activity of Integral Lemon Pectin Extracted via Hydrodynamic Cavitation. ChemistryOpen 2020, 9 , 628-630. [CrossRef]

18. Presentato, A.; Piacenza, E.; Scurria, A.; Albanese, L.; Zabini, F.; Meneguzzo, F.; Nuzzo, D.; Pagliaro, M.; Martino, D.F.C.; Alduina, R.; et al. A New Water-Soluble Bactericidal Agent for the Treatment of Infections Caused by Gram-Positive and Gram-Negative Bacterial Strains. Antibiotics 2020, 9, 586. [CrossRef]

19. Thommes, M.; Kaneko, K.; Neimark, A.V.; Olivier, J.P.; Rodriguez-Reinoso, F.; Rouquerol, J.; Sing, K.S. Physisorption of gases, with special reference to the evaluation of surface area and pore size distribution (IUPAC Technical Report). Pure Appl. Chem. 2015, 87, 1051-1069. [CrossRef]

20. Chang, S.-S.; Clair, B.; Ruelle, J.; Beauchêne, J.; Di Renzo, F.; Quignard, F.; Zhao, G.-J.; Yamamoto, H.; Gril, J. Mesoporosity as a new parameter for understanding tension stress generation in trees. J. Exp. Bot. 2009, 60, 3023-3030. [CrossRef]

21. Groen, J. Critical appraisal of mesopore characterization by adsorption analysis. Appl. Catal. A: Gen. 2004, 268, 121-125. [CrossRef]

22. Zhbankov, R.G.; Firsov, S.P.; Korolik, E.V.; Petrov, P.T.; Lapkovski, M.P.; Tsarenkov, V.M.; Marchewka, M.K.; Ratajcak, H. Vibrational spectra and the structure of medical biopolymers. J. Mol. Struct. 2000, 555, 85-96. [CrossRef]

23. Cichosz, S.; Masek, A. IR Study on Cellulose with the Varied Moisture Contents: Insight into the Supramolecular Structure. Materials 2020, 13, 4573. [CrossRef] [PubMed]

24. Berezin, K.V.; Shagautdinova, I.T.; Chernavina, M.L.; Novoselova, A.V.; Dvoretskii, K.N.; Likhter, A.M. The experimental vibrational infrared spectrum of lemon peel and simulation of spectral properties of the plant cell wall. Opt. Spectrosc. 2017, 123, 495-500. [CrossRef]

25. Oh, S.Y.; Yoo, D.I.; Shin, Y.; Seo, G. FTIR analysis of cellulose treated with sodium hydroxide and carbon dioxide. Carbohydr. Res. 2005, 340, 417-428. [CrossRef] [PubMed]

26. Widsten, P.; Dooley, N.; Parr, R.; Capricho, J.; Suckling, I. Citric acid crosslinking of paper products for improved high-humidity performance. Carbohydr. Polym. 2014, 101, 998-1004. [CrossRef] [PubMed]

27. Arslanoglu, H.; Altundoğan, H.S.; Tumen, F. Preparation of cation exchanger from lemon and sorption of divalent heavy metals. Bioresour. Technol. 2008, 99, 2699-2705. [CrossRef] 
28. Bondancia, T.J.; De Aguiar, J.; Batista, G.; Cruz, A.J.G.; Marconcini, J.M.; Mattoso, L.H.C.; Farinas, C.S. Production of Nanocellulose Using Citric Acid in a Biorefinery Concept: Effect of the Hydrolysis Reaction Time and Techno-Economic Analysis. Ind. Eng. Chem. Res. 2020, 59, 11505-11516. [CrossRef]

29. Segal, L.; Creely, J.; Martin, A.; Conrad, C. An Empirical Method for Estimating the Degree of Crystallinity of Native Cellulose Using the X-Ray Diffractometer. Text. Res. J. 1959, 29, 786-794. [CrossRef]

30. Scurria, A.; Sciortino, M.; Presentato, A.; Lino, C.; Piacenza, E.; Albanese, L.; Zabini, F.; Meneguzzo, F.; Nuzzo, D.; Pagliaro, M.; et al. Volatile Compounds of Lemon and Grapefruit IntegroPectin. Molecules 2020, 26, 51. [CrossRef]

31. Satyamurthy, P.; Jain, P.; Balasubramanya, R.H.; Vigneshwaran, N. Preparation and characterization of cellulose nanowhiskers from cotton fibres by controlled microbial hydrolysis. Carbohydr. Polym. 2011, 83, 122-129. [CrossRef]

32. Karabourniotis, G.; Horner, H.T.; Bresta, P.; Nikolopoulos, D.; Liakopoulos, G. New insights into the functions of carbon-calcium inclusions in plants. New Phytol. 2020, 228, 845-854. [CrossRef]

33. Bhattacharjee, S. DLS and zeta potential-What they are and what they are not? J. Control. Release 2016, 235, 337-351. [CrossRef] [PubMed]

34. Ang, J.F. Water Retention Capacity and Viscosity Effect of Powdered Cellulose. J. Food Sci. 1991, 56, 1682-1684. [CrossRef]

35. Mahato, N.; Sharma, K.; Sinha, M.; Baral, E.R.; Koteswararao, R.; Dhyani, A.; Cho, M.H.; Cho, S. Bio-sorbents, industrially important chemicals and novel materials from citrus processing waste as a sustainable and renewable bioresource: A review. J. Adv. Res. 2020, 23, 61-82. [CrossRef] [PubMed]

36. Chemat, F.; Vian, M.A.; Cravotto, G. Green Extraction of Natural Products: Concept and Principles. Int. J. Mol. Sci. 2012, 13, 8615-8627. [CrossRef] [PubMed] 